\title{
IDIOMA Y SABERES OTOMÍES. RESCATE Y PRÁCTICA EN LA VIDA COTIDIANA
}

\author{
Fabiana Sánchez Plata \\ fsanchez@uaemex.mx \\ Instituto de Ciencias Agropecuarias y Rurales \\ Cristina Chávez Mejía \\ cchavezm@uaemex.mx \\ Universidad Autónoma del Estado de México
}

\section{RESUMEN}

Este artículo contiene los resultados de la investigación sobre el papel de las mujeres otomíes en la transmisión del idioma en el ámbito de la vida cotidiana. Se buscó rescatar la relevancia del idioma materno para el funcionamiento de la vida social de los otomíes y reconocer la relevante función de las mujeres para que el otomí siga siendo un idioma vivo. Este es, particularmente para las mujeres, el referente generacional, la herramienta a través de la cual han adquirido un amplio reservorio de saberes. Desde el confinamiento de sus roles tradicionales, ellas encuentran en la esfera doméstica un espacio de privacidad y de confianza para hablarlo y forjar el respeto de los demás. La práctica cotidiana de sus saberes femeninos en ese espacio constituye uno de los vehículos que prolonga la vigencia y el desarrollo de su idioma.

Palabras clave: idioma otomí, mujeres otomíes, vida cotidiana, saberes femeninos.

\section{ABSTRACT}

This article analyses the role of Otomí women in the transmission of language by carrying out activities of daily life. The focus is on two points. First, it is analyzed the importance of language within social life for the Otomí women and men; and second, to make visible the 
importance of women to keep the Otomí language alive. Through generations, the language for women has been a tool to have and conserve local knowledge that allows them to accomplish their female daily activities and fulfill their social roles. Local language is not only important for women to carry out specific daily female activities, but also by speaking it, women acquire respect. Women feel confident and find a space for privacy in the domestic sphere to speak their local language. Therefore, the domestic life for women represents an opportunity for them to conserve and develop their Otomí language.

Key words: Otomí language, Otomí women, daily life.

\section{INTRODUCCIÓN}

La especie humana recibe de sus ancestros una herencia genética, lingüística y cognitiva. Esta se manifiesta en la diversidad genética, lingüística y contenidos de sabidurías (Toledo y Barrera-Bassols, 2008). Confirmamos con ello que los idiomas indígenas son herencias ancestrales, de las que se han valido las etnias para construir su historia social, ambiental y cultural. La categoría de idioma se adquiere al reunir una estructura gramatical, una fonética y códigos lingüísticos propios. En la evolución de las sociedades indígenas, el idioma es el vehículo que ha posibilitado la comunicación de los pensamientos que acompañan su transformación. Los saberes, son códigos, signos, formas de representación, algo que existe pero cuya explicación resulta solo para quienes están concernidos, y en su creación interviene la experiencia personal y colectiva. El idioma es un saber, al mismo tiempo conductor y portador de saberes. El idioma ha posibilitado a los otomíes salvaguardar saberes que les permiten funcionar en la vida diaria.

Esta investigación se sostiene teóricamente de tres pilares: el de la vida cotidiana, el idioma y los saberes, todos atravesados por la perspectiva de género. Se buscó analizar, desde el espacio doméstico y la puesta en práctica de los roles de género, la transmisión del idioma otomí y los saberes de género de que es portador. La pregunta que interesa responder es 
¿qué hacen las mujeres, distinto de los hombres, que posibilita la enseñanza del idioma materno?

El trabajo etnográfico se realizó en Pueblo Nuevo, Acambay, en dos tiempos: una estancia de 6 meses en el año 2005 y un regreso en 2009 que duró un mes. De ambas etapas se obtuvieron 24 entrevistas en profundidad, se recogieron tres historias de vida de parteras y una amplia información etnográfica a partir de la observación directa. Las mujeres hablaron en otomí y español, tuvieron así entrevistas en otomí, en español y otras en ambos idiomas. Fueron transcritas en diferentes momentos. No se solicitó traductor o intérprete para las entrevistas en otomí, estas fueron traducidas e interpretadas por una de las investigadoras que conoce y habla este idioma. Para la escritura en otomí se solicitó la opinión de expertos locales (un profesor y dos profesoras) que han redactado textos de relevancia local y un diccionario en el otomí de Acambay.

Damos cuenta en este artículo que el idioma otomí sobrevive a pesar del transcurrir de estas sociedades en un mundo globalizado y la discriminación de que han sido objeto sus hablantes. El habla y la transmisión del idioma son atravesadas por las variables de género y generación. Las mujeres se mantienen leales a su idioma; sin embargo, se puede percibir que la relación entre jóvenes generaciones e idioma es débil. Los jóvenes y niños asimilan los códigos lingüísticos del otomí, pero el nivel de habla es bajo. Cuando lo hablan, lo hacen en el espacio privado y con poca preferencia frente al español.

El espacio doméstico es el lugar donde se cristalizan los roles femeninos y donde las mujeres, poseedoras de los códigos lingüísticos, pasan la mayor parte del tiempo en su quehacer cotidiano. En su labor reproductiva y productiva retransmiten la enseñanza de los deberes femeninos y masculinos teniendo como guía al idioma materno. Los hombres también participan en esta recreación del idioma en espacios de carácter público, socializando entre adultos. Es el espacio doméstico donde tienen lugar las actividades productivas y el trabajo reproductivo las nuevas generaciones; allí, niños, jóvenes y adultos encuentran un punto de encuentro para la socialización del idioma. 


\section{LA RELACIÓN VIDA COTIDIANA, IDIOMA Y GÉNERO}

Como todos los objetos de estudio, la vida cotidiana puede tener distintas vertientes para su análisis. Los referentes teórico-conceptuales podrían ofrecer información detallada y suficiente para explicarla por sí misma. Lo ideal es balancear los dos niveles: el teórico y el práctico. Desde el plano empírico, el reto es observar el desempeño de la vida cotidiana a partir de un mínimo de indicadores que permitan entenderla y explicarla de manera más fácil. Por otro lado, es importante plantear un abordaje teórico que lleve al entendimiento de la vida cotidiana y, al mismo tiempo, permita la interpretación empírica.

Desde la sociología del conocimiento, la vida cotidiana es entendida como la construcción social de la realidad, el espacio donde se manifiesta la riqueza de la diferencia, la alteridad en acción, el otro asumiéndose a sí mismo y desarrollando las conductas que definen al ser humano como ser social (Berger y Luckmann, 1979). La realidad social abarca el escenario del mundo privado, público, objetivo y subjetivo, moldeados por el pensamiento y las acciones de hombres y mujeres.

Los estudios de género enfrentan el reto de recuperar críticamente las propuestas de la sociología de la vida cotidiana en su sentido general y, a la vez, recurrir a nuevas categorías analíticas para revelar el transcurrir de las interacciones de los hombres y las mujeres. En esta tesitura, la categoría de género tomada como herramienta analítica no solo mira las problemáticas de las mujeres, sino la vida social y, de una manera global, las relaciones entre los sexos. Desde un inicio, esta categoría innovó las miradas hacia las situaciones y condiciones de las mujeres y ha ayudado a explorar la relación entre lo privado, lo público, lo íntimo y el vínculo entre las relaciones de producción y reproducción, así como los procesos de elaboración de las identidades sexuales (Maier, 1998).

La perspectiva de género se concibe como una construcción social sistemática de lo masculino y lo femenino a partir de los datos biológicos (el sexo) (Lagarde, 1990). Es a 
través de esta perspectiva que viejos problemas son tomados y mirados de una manera renovada. La utilidad de esta descansa en las nuevas interpretaciones de los estudios de la mujer en relación con el hombre (Harding, 1987). De ello se descubre que este no es el sujeto singular, aunque durante siglos la producción académico-científica no tuvo más lenguaje que aquel dominado por lo masculino. Antes del fin del siglo XIX nadie imaginó o admitió que la mujer y el hombre pudieran ser presentados como sujetos diferentes. Se recurre a la idea del «otro», antes desarrollada por Simone de Beauvoir, para reclamar el espacio social de las mujeres. El «otro» es la vida del femenino que se presenta no como la negación del masculino, sino el «igual» (Irigaray, 2002). En este caso se refiere al femenino como sujeto cultural, con distintas formas de «ser» y de «hacer».

La perspectiva de género no es partidaria de que exista una diferencia cognitiva del lenguaje o que haya un lenguaje para cada sexo; pero sí en cambio un lenguaje sexuado, regulado por la cultura y las normas sociales matizadas en la vida cotidiana. Por un lado, la perspectiva de género contribuye a la delimitación del comportamiento lingüístico socialmente permitido para hombres y mujeres. Los hombres tienen una preponderancia discursiva en los espacios públicos, en los que encuentra un mejor acomodo. Por otro lado, mientras la mujer se incorpora al espacio privado queda excluida de un idioma público, pero desarrolla otro que posibilita la comunicación en el espacio privado, que es donde descansa la reproducción de los roles tradicionales. Y justamente en este espacio se pone en práctica la acción socializante de la lengua, con mayor participación de la mujer, quien asume esta tarea como un asunto inherente a su naturaleza femenina (Buxó, 1988). 


\section{IDIOMA, SABERES Y SOCIEDAD}

La relación entre idioma y sociedad es histórica. Este existe en tanto estructura lingüística definida y particular, por lo que sociedad e idioma se determinan mutuamente. Todo ser humano nace y se desarrolla inmerso en un ambiente social, de donde toma los códigos lingüísticos para la comunicación verbal con los otros. Aunque no es condición, el idioma motiva y posibilita la integración del individuo en sociedad, la asimilación y la transformación de la cultura y el ambiente social (Benveniste, 1999). La diversidad de idiomas, la diversidad de las culturas, y sus cambios, hacen asomar la naturaleza convencional del simbolismo que las articula. El idioma es, en definitiva, el vínculo más vivo entre los seres humanos.

El idioma cumple más de una función, siendo la expresión oral y la reproducción de la realidad, que son las de primer orden (Benveniste, 1999). La oralidad hace particular la relación entre idioma, individuos y sociedad. En esta relación, el idioma alcanza su dimensión histórico-social. En dicha dimensión, este puede ser resultado de la evolución de las sociedades. Ello quiere decir que se mantiene o se pierde dentro del proceso de evolución de las sociedades.

Desde la antropología y la etnografía feminista se cuestionan las categorías teóricoepistemológicas androcéntricas de las que se han valido para construir históricamente el conocimiento. La presencia más marcada de las mujeres en campos de conocimiento científico, la tecnología o el conocimiento empírico, ha tenido poca utilidad para que dejen de ser un sector subalterno y víctimas del patriarcado en los espacios donde desencadenan sus actividades cotidianas. En ese tenor de ideas, voces como las de Buxó (1988), Castañeda (2006), Gregorio (2006) y Hernández (2003) buscan resignificar los campos de estudio de las mujeres, donde merecen ser pensadas, presentadas y descritas incluso por ellas mismas. Es decir, reconocer a las mujeres como sujetas hacedoras, poseedoras de conocimientos y socializadoras de estos. 
En el campo del saber, las mujeres pueden investigar y ser investigadas, enseñar y aprender de otras (Castañeda, 2006). Esto nos reenvía a otro precepto muy fuerte que consiste en reconocer que ellas desde sus espacios, quizá invisibilizados, tienen saberes y hay saberes concretos a cada una. Se suma a ello que esos saberes, conocimientos, habilidades, hallazgos y descubrimientos son herencia de un colectivo y su misión es hacerlos permanecer como parte de sus aportes a sus sociedades.

El saber es una construcción social resultado de un proceso continuo y permanente, fundamentado en las experiencias de los sujetos(as), mediado por elementos que permiten identificar genérica y socialmente el deber de hombres y mujeres de una sociedad concreta. Pertenece a un orden cultural y simbólico, y sobre este descansan significados, valores y percepciones particulares que sirven como eje conductor de la vida cotidiana de los seres humanos.

El saber que se reproduce en lo cotidiano es una estrategia objetiva y al mismo tiempo normativa. Objetiva en tanto que es la suma del saber cotidiano de una época, de un estrato social. Es normativa toda vez que para que un estrato o integración cumpla su función, es la totalidad de tal estrato o integración la que debe apropiarse de este saber cotidiano. Todas las sociedades son poseedoras de un saber, determinado por la suma de los conocimientos que todo individuo interioriza para poder existir y moverse en su ambiente. El mínimo de saber para un individuo es el idioma (Heller, 1991).

El saber primario que todo hombre y mujer deben tener como requisito posibilitador de la aprehensión de otros saberes es el idioma. Este se aprende en una interacción con semejantes y frente a la cotidianidad del grupo doméstico y de la comunidad. Es por ello que el idioma es considerado un saber individual y colectivo. Como primer saber sirve de hilo conductor de los aprendizajes del saber genérico, en términos de cómo guiar a un hombre o mujer sobre lo que debe saber en la vida. 
Para el caso de los otomíes, la adquisición de los saberes en función del género ocurre en el marco de una instrucción informal por las más expertas. Toman su responsabilidad, la obligación de prolongar los conocimientos, despertar habilidades y crear actitudes en las jóvenes generaciones. De esa forma fue como se asimilaron los conocimientos, habilidades y actitudes con que cuentan ahora y que ya son parte de su patrimonio de género.

En esta perspectiva, el saber cotidiano de las generaciones adultas es el fundamento del saber cotidiano de las sucesivas. Las generaciones de mujeres, al ir diseñado la forma en que heredarán sus saberes, toman conciencia sobre el valor y utilidad que tiene la transmisión de sus saberes; esto hace suponer que solo a ellas corresponde definir si se trata o no de un saber. Las mujeres con su información y sus saberes parecen generaciones orientadas hacia un pasado de cual obtienen su fortaleza femenina y lo que saben toma un valor.

\section{PUEBLO NUEVO: HISTORIA Y PRESENTE}

El surgimiento de movimientos indígenas que buscaban, entre otras cosas, la reivindicación de sus derechos culturales, y dentro de ellos el idioma materno, no pudo ser más oportuno en la década de los noventa. Los pueblos indígenas querían ser reconocidos en el libre ejercicio de su cultura y la inclusión de los derechos culturales en la política de Estado. En la práctica esto equivalía a la libre decisión de regirse conforme sus costumbres, su forma de organización colectiva y el rescate del idioma. Fueron grandes los esfuerzos para la enseñanza del idioma materno, mandatados dentro de una política de Estado. Como respuesta, en territorios con población indígena se buscó integrar al sistema educativo en preescolar y primaria, la alfabetización en idioma materno; se tradujeron textos importantes como la Constitución Mexicana, se escribió en lengua materna la historia relevante de los pueblos, se escribieron y corrigieron diccionarios y se fortaleció la tarea del historiador local. 
Aparentemente, las acciones emprendidas por el Estado desde las instituciones educativas afianzó el compromiso de los docentes para empezar a revalorar su cultura y el idioma frente a grupo; sin embargo, el espacio público y el privado se mantuvieron divididos en torno a la enseñanza y habla del idioma materno. De cierta manera, el espacio público fue escenario para repensar la relación entre grupos indígenas y el Estado. La lucha de los pueblos indígenas es histórica, ha generado grandes movimientos sociales, siendo el de 1994 el más reciente y el que reabrió los espacios académicos para el estudio de las etnias y sus idiomas, dada su importancia social y cultural.

Existen en el país 62 etnias, cada una distinta de otra, que tienen como elementos de identidad el territorio, el idioma, y también otras características, como son: las prácticas rituales, las normas, las formas de relación y las estrategias de vida. Las 62 etnias dan cuenta de un número equivalente de idiomas con distinto número de hablantes. Según datos del INEGI (2010), existen en México 13,562,702 hablantes de alguna lengua indígena. El Estado de México tiene 376,830 hablantes, que probablemente son bilingües, y se ubica en el séptimo lugar en hablantes de lengua indígena. Las lenguas originarias de la entidad son cinco: mazahua, otomí, matlazinca, náhuatl y tlahuíca. Aparentemente, los hablantes de lengua indígena se sitúan en ciudades pequeñas y de carácter rural, y el sexo masculino es el dominante en habla indígena. Los municipios con mayor población de carga lingüística indígena otomí son: Temoaya, Morelos, Acambay, San Andres Timilpan, Chapa de Mota y Aculco.

El municipio de Acambay se localiza al norte del Estado de México, tiene de vecinos a los municipios de Aculco del lado norte, Timilpan y Atlacomulco del lado al sur, y Temascalcingo del lado Este. Su población es de 85,631 personas. Pueblo Nuevo pertenece a Acambay y se sitúa al este del municipio, colinda con comunidades de San Mateo el Viejo (Temascalcingo), Guadalupe, la Soledad y Tixmadeje. Este pueblo es habitado por 2, 397 personas (INEGI, 2010). 
Durante el periodo posrevolucionario, la gente de Pueblo Nuevo fue testigo y protagonista de importantes conflictos, motivados por la falta de tierras de cultivo, contra los pueblos vecinos de la Magdalena, Barrio de Guadalupe, San Mateo el Viejo y la Soledad. Fueron conflictos de consecuencias fuertes, muchas vidas de líderes agrarios y campesinos pobres se sacrificaron y algunas familias se fracturaron.

Como resultado de su propio proceso histórico se ha dividido el pueblo en dos barrios: primero y segundo. Cada uno tiene a su delegado municipal y una oficina delegacional, una escuela primaria y preescolar. El pueblo cuenta con biblioteca, escuela secundaria, telesecundaria, clínica de salud y salón ejidal.

La infraestructura básica que está al servicio de la población se compone de drenaje, electricidad, agua potable (hay un pozo para extraerla para toda la comunidad), una carretera que conecta hacia Temascalcingo y Acambay, y carreteras de terracería que hacen conexión con La Soledad, San Mateo el Viejo y Guadalupe. El servicio de transporte es brindado por taxis colectivos que llevan a la cabecera municipal. Desde el 2000 se disparó el uso indiscriminado del vehículo privado.

Desde su propia etnicidad, los pobladores de Pueblo Nuevo han buscado cargos de representación popular, y partir de esta surgieron dos presidentes municipales originarios de Pueblo Nuevo, con lo que se rompió la hegemonía externa y de la cabecera municipal para proponer y elegir al representante.

La principal actividad que sostiene económica y socialmente a esta sociedad es la agricultura de temporal. Las tierras son de régimen ejidal, herencia del Reparto Agrario de 1936. Se encuentra en la planicie, mientras que las tierras de tipo comunal se localizan en el monte. En ambos tipos de suelos se cultiva maíz criollo. Actualmente, la agricultura se mantiene solo por las generaciones de campesinos y campesinas que reconocen el valor del maíz y del oficio de trabajar la tierra. La actividad artesanal es principalmente la trenza de popote de trigo, materia prima para elaborar bolsas, sombreros, canasta, tapetes, entre otros 
productos. La artesanía de popote ha dado identidad y sustento económico a esta sociedad. Se elabora en los domicilios de cada familia y en esta participan mujeres y hombres de distintas generaciones, organizados por género y generación. La trenza se teje por niños y ancianos y adultos maduros, quienes colectan el popote y compran la trenza que otros tejen, elaboran la artesanía, la llevan a planchado y dan los acabados. En cambio, todos pueden participar en la comercialización de lo producido. El mercado de esta artesanía es muy amplio, se vende en los alrededores de Acambay, Morelia, San Juan del Río y otras ciudades del norte, como Monterrey, Tijuana, Ciudad Juárez. La producción de la artesanía en el ámbito privado se rescata como espacio de socialización y recreación del idioma. El comercio de la artesanía se acompaña de otras mercancías que los propios otomíes de Pueblo Nuevo van adquiriendo en sus recorridos de venta.

Por otra parte, existe un amplio sector de profesores de nivel preescolar, primaria, secundaria y universidad (son los menos), cuyos empleos están en la misma comunidad y en otras comunidades de la región. Hay también un número importante de funcionarios de gobierno trabajando en el ayuntamiento, en las instancias de la Coordinación para el Desarrollo de los Pueblos Indígenas (CDI) de Atlacomulco.

Existen otros oficios que las personas ejercen sea por temporadas o de manera permanente: empleadas domésticas en la ciudad de México, obreros de la construcción, choferes, entre otros. Desde el año 2000 al día de hoy (2011), la migración de hombres y mujeres a Estados Unidos de Norteamérica vino a cambiar la dinámica de la migración regional y de corto tiempo de estas sociedades. Aunque se trata de una migración bisoña, están viéndose las consecuencias por la alta preferencia de los jóvenes por este destino. 


\section{¿EXISTEN EN LOS OTOMÍES SABERES DE GÉNERO?}

Existen diversas respuestas a esta pregunta. Empezaremos por señalar que lo que llamamos ciencias, conocimientos y saberes no son producto de procesos neutros con relación al género. La construcción de la ciencia-técnica se ha hecho con poco reconocimiento a la contribución de las mujeres. En las sociedades étnicas la situación es más crítica: los saberes no son apreciados como tal y las mujeres no se ven dentro de la producción y prolongación de estos. Por lo tanto, así como el conocimiento empírico tiene una diferenciación en su creación, coexiste una diferenciación de habilidades y acervo cognitivo por género. Existen saberes colectivos creados a partir del lenguaje oral, donde participan hombres y mujeres desde sus distintas historias, recursos y condiciones de género.

Las sociedades étnicas, en particular la otomí o ñahñu de Acambay, fueron y siguen siendo (cada vez menos) organizadas bajo una relación simbólica entre el cosmos, la tierra y el cuerpo humano. Ello permite explicar el pensamiento otomí y la forma como se relacionan con los otros elementos del cosmos, del universo. Varios son los saberes que los otomíes resguardan a través de sus prácticas cotidianas. Los saberes son códigos, signos, formas de representación, algo que existe pero cuya explicación resulta solo para quienes están concernidos. Interviene la experiencia personal y colectiva. El idioma es un saber, al mismo tiempo conductor, portador de saberes. El idioma ha posibilitado a los otomíes salvaguardar saberes que les permiten funcionar en la vida diaria.

Esta sociedad fue por largo tiempo reconocida y respetada por las sociedades vecinas. Hasta los años setenta corría el rumor de ser prolífera en chamanes o curanderos. Un oficio masculino, cuya misión era salvar la vida de las personas, sea por enfermedad o embrujamientos. El brujo o curandero sembró un prestigio que traspasó el espacio doméstico-local. Muchas eran las personas que solicitaban los servicios de estos brujos o curanderos para resolver situaciones de salud o conflictos de distinta naturaleza. Los hombres fueron bien reconocidos por sus saberes para la sanación o para provocar el mal. Fueron médicos brujos de profundos saberes sobre enfermedades del cuerpo. 
La materia prima de la cual se servían estos oficios era el saber sobre los usos y beneficios curativos de las plantas medicinales, así como el vínculo con otros seres de la naturaleza y el cosmos. Se conoce poco sobre la transición de esos saberes e incluso la forma de ejercicio de esos oficios, porque el común de la población mantiene a esos oficios como un tabú. Algún dolor fuerte está detrás de ese silencio u ocultamiento de la existencia de dichos oficios. Aunque de vez en vez, en sus relatos, las mujeres agradecen haber sanado de una enfermedad mortal por los remedios del curandero o brujo. Y en eso la fuerza o energía masculina era determinante.

Las mujeres también brillaron por el conocimiento de la medicina aplicada a la sanación de enfermedades atribuidas a lo femenino. El oficio de parteras y curanderas no fue ejercido por todas; sin embargo, el conocimiento de cómo cuidar o proporcionar los cuidados ligados a la reproducción femenina permanece como un patrimonio sociocultural del género femenino. Tratándose de una sociedad de recursos económicos escasos, los saberes que ellas han heredado son recursos gratuitos que ponen a disposición de otras mujeres en torno a la salud.

Ellas se abocaron a saberes concernidos a la salud reproductiva y lo femenino: la salud, la vida y la muerte. Los hombres recibieron esta información, lo cual no quiere decir que sean ellos quienes la lleven a la práctica. Se acumula conocimiento que tiene utilidad solo para evaluar la capacidad de la mujer para resolver los problemas de salud de los otros. Aunque pueden ser transmitidos vía verbal o escrita, el saber femenino para tratar la salud reproductiva femenina fue transmitido en su forma oral. El objetivo es prolongar en sus congéneres el saber que ayudará para dar continuidad a los elementos identitarios de género. En la praxis, es el resultado de las experiencias que cada mujer y cada hombre han sintetizado y concretizado dentro de un proceso sociocultural e histórico. Este fue creado a partir de su propia identidad de ser mujeres, de la misma manera que sucede en otras configuraciones culturales. 
Para ciertos saberes no es suficiente el uso del idioma en su forma oral, se recurre también al idioma de manera gráfica. Es el caso de la elaboración de textiles y bordado de prendas de vestir, por su grado de dificultad y el manejo de la simbología cosmogónica y significados. Presentamos en el siguiente cuadro los saberes más representativos atribuidos al sexo femenino.

\section{Cuadro 1. Rescate y conservación de saberes femeninos.}

\begin{tabular}{||l|l|l||}
\hline \multicolumn{1}{|c|}{ SABERES } & \multicolumn{1}{c||}{ ¿UIÉN LE ENSEÑO? } & ¿EN QUÉ IDIOMA? \\
\hline$-\begin{array}{l}\text { Uso de las plantas medicinales } \\
\text { enfermedad }\end{array}$ & $\begin{array}{l}\text { Abuela, madre, suegra } \\
\text { Hermana, cuñada. }\end{array}$ & Otomí \\
\hline$\quad$ Tratamientos de la enfermedad & & \\
\hline $\begin{array}{l}\text { Tejer: ayate, fajas, quesquémetl } \\
\text { Bordar: simbología en la vestimenta }\end{array}$ & $\begin{array}{l}\text { Abuela, madre, hermana, } \\
\text { cuñada, amiga, prima. }\end{array}$ & Otomí \\
\hline \hline
\end{tabular}

Fuente: Elaboración propia con información aportada por las mujeres.

El saber de los usos medicinales se combina entre la diversidad florística de la casa, del llano y del monte, y el conocimiento de sus propiedades medicinales. Este se obtiene de la información y la práctica en distintas etapas de la vida. A pesar de no haber recibido instrucción formal, curan a otras mujeres basándose en el reconocimiento del cuerpo femenino y la experiencia propia. Atender a otras mujeres en estados propios de lo femenino aparece como una prolongación de las funciones reproductivas. El universo de atención se concentra en el servicio gratuito a familiares, amigas y vecinas.

El aprendizaje ocurre desde la niñez, en su participación como «ayudanta» en los trabajos de parto de la madre, suegra, hermana, cuñada, entre otras. Tal aprendizaje se ve reforzando con la experiencia personal. De esa manera se construye un saber personal, proveniente de la necesidad y el interés por cuidar la vida propia y ajena. Hacerse cargo de la salud en problemas particulares de las mujeres otorga un grado de satisfacción, aun sabiendo que no será reconocida como ótíté (parteras) y que tal reconocimiento tampoco es determinante para servir a otras otomíes. 
Ocurre, ciertas veces, que usan sus saberes para curar o salvar la vida de otras mujeres solo estando al amparo del Kha-Dios.

De mi tercer hijo tuve un parto de mucho dolor. La pobrecita de mi suegra era la que me atendía. Yo me puse mal pero me esperé a que ella regresar, ya un poco noche le mandé al muchacho -ba nu ri meme, di xi da ekua- vete a ver tu güela, dile que venga acá. Si vino corriendo, llego y me vio, y me dijo, mmh está muy complicado, si no sale pronto se te va a morir. Yo me asusté mucho, luego me dijo, voy a meter mi mano, ¡híjolej sentí que me moría, entre rezando y todo, me tuvo que cortar hasta mi parte de arriba pa’ que pudiera sacar el niño. Esa vez, tardé mucho pa’ componerme, pero mi suegra aquí estuvo todos los días, me curaba con maguey asado y me lavaba, mmmh, ¡cuánto no sufrí esa vez! Ella nomás pa’ consolarme me decía, höt’i ya xa ñ’othe- guántate ya se está curando (Margarita, 58 años).

El parto era un acontecimiento porque expresaba la llegada de una vida, un nuevo integrante a la familia, y una experiencia particular para la parturienta y la partera (familiar). La presencia del padre durante el parto es poco común, sí en cambio están presentes otras acompañantes: madre, hijas, nueras, primas o cuñadas. Las parturientas con mayor experiencia saben cómo reaccionar ante la dificultad. En cuanto se presentan los síntomas del parto, buscan ayuda o se las arreglan para pasar la situación.

Yo siempre llevé mis cuentas. Las señoras me preguntaban Tengur pa bi b’edi pa gi ähä.-¿cuántos días te faltan pa’ que te quedes a ver los ratones?-bi medi yoho zänä- me faltan dos meses, le decía yo. Cuando se llegaba el día, ya no salía de la casa, nomás andaba aquí en la casa, de repente sentía un dolor y corría a preparar el petate, los trapos, y le mandaba a mis hijos a avisarle a mi mamá y a mi señor (Virginia, 67 años).

La parturienta solitaria fue poco frecuente. Cuando se daba ese caso, se trataba de una mujer que depositaba en su propia atención al parto, un sentimiento de prestigio, fuerza y 
autosuficiencia solo asistido por la divinidad: «Dios ayúdame» -Sitata nföts’i- o «Virgencita ayúdame»-Sinana nföts’i-.

Vale decir que ciertas veces, la práctica de los saberes llega en momentos no previstos.

He tenido muchas experiencias, la más difícil fue cuando ya había nacido su bebé y no bajaba la placenta. Eso nunca me había pasado, y dije, ¿ ora cómo le hago?, entonces pensé, la voy a bajar de la cama, y sí lo hice, la bajé y la tiendo en el petate; le di sobadas en el vientre de arriba para abajo, le daba de tomar el too (té que sirve para acelerar las contracciones) y no bajaba, pus con todo el dolor que le empiezo a jalar y la fui jalando con mucho cuidado; ya que salió un poco, le amarré un hilo mientras la seguía sobando y le daba té. Cuando vi que la placenta iba bajando poco a poco, ya le decía a la pobrecita de mi nuera- ka ri nzedi ya xa juadi- ten fuerza, ya va a terminar (Catalina, 60 años).

Ciertas veces, estar o no en un parto ha sido pretexto para fracturar las relaciones entre las otomíes.

Yo no me comprometo con otras señoras, una vez le pasó lo mismo a una vecina, su mamá vino a pedirme de favor que fuera a verla, yo quería decirle que no pero fui para que no piense que me hago la orgullosa nomás porque sé. Ya cuando la muchacha estaba bien, se hizo muda, ni me agradece lo que yo la ayudé. Mis hijos no quieren que ayude a la gente, me dicen, jno te vayas ma' que tal que te van a comprometer! (Virginia, 67 años).

Una visita a las mujeres que acaban de parir tiene que ser acompañada del ofrecimiento del atole-t'ei-, pan-thuhme- comida y tortillas -hme-, eso constituye parte de la solidaridad entre mujeres o la procuración de un apoyo afectivo y simbólico que solo se manifiesta en el ámbito doméstico.

Tanto el parto como el posparto necesitan cuidados donde están explícitos los conocimientos de las mujeres. Antes que otro baño, el de infusión de hierbas medicinales es 
obligado para ayudar a la recuperación física del cuerpo femenino. La infusión es combinación de hojas de árbol y plantas de tres orígenes: Monte: ocote (tudi), madroño (nthaxi), té de monte (m'axuk'ani); cultivadas: manrubio (ñetö), y silvestres: pexto (jut'o), jarilla (desutsintsu), tepozán (nhaza), capulín (dese), pirú (zagithuni). El baño con infusión sustituye al baño en Temazcal, que pocas mujeres tenían en su casa. A la fecha, el baño de parto es una práctica muy minimizada, desplazada por la intervención de los centros de salud donde las jóvenes madres son llevadas a parir.

\section{TEJER SU VESTIMENTA}

Para la etnia otomí, así como la mazahua, existe una relación entre el vestuario y su idioma. Estos solo pueden ser trascendentes en la medida en que se conciben como elementos identitarios de una cultura.

El vestuario otomí en su forma original es parte de la tradición, encierra una gama de significados, colores y diseños, expresa el espíritu del tiempo y es indudablemente un aliado firme de la cultura. Es el resultado de ser diferente, comunicación no verbal que intenta decir algo a la sociedad en un lenguaje visual en todos los aspectos (Vázquez, 2000). Es, al mismo tiempo, portar en el cuerpo un significado y un significante. El significado revela la identidad y pertenencia de grupo, mientras el significante denota la interpretación que cada individuo da al significado. Luego entonces el idioma es una vía para la trasmisión del significante y significado de un individuo a otro de una misma etnia.

En la enseñanza-aprendizaje de los saberes es natural enseñar en otomí, el idioma con el que han nacido hombres o mujeres. Hay conocimientos particulares adquiridos con el sello de exclusividad del género femenino, como el tejido de las prendas de vestir o de los instrumentos del trabajo agrícola. Pero el idioma sigue como herramienta necesaria que antecede cualquier otro saber, pues al usar y entender el significado de símbolos, el mundo toma su propio significado. 
Formarse como tejedora o bordadora de sus prendas de vestir no escapa de un proceso de aprendizaje fundamentado en el dominio del código lingüístico. La formadora (madre y abuela) poseedoras de un «saber qué» (simbología tomada de la naturaleza) y un «saber cómo» (técnica) que transfiere a otra mujer, pasa por la función de «ayudante», donde la aprendiz se apropia de los instrumentos y los medios de trabajo para tejer-pe- y bordarnjöt'i- la indumentaria femenina y los instrumentos de trabajo agrícola. No hay una enseñanza por azar, sino intencionada: preparar a la mujer para el desempeño de sus roles de madre y esposa en el hogar y en las actividades agrícolas.

Por su grado de complejidad, por regla, las mujeres empezaban a tejer algo de menor dificultad. La elaboración del ayate -r'onjua-, mecapal -ndude-, costal -r'oza- y morral es la prueba de iniciación. Ese saber tejer tiene como condición la obtención del Ixtle, para lo cual hay otro proceso que inicia con cortar las pencas de maguey, asarlas y tallarlas, sacar el ixtle, lavarlo, ponerlo a secar y hacer el hilado con un pequeño instrumento conocido como «malacate». El que la mujer tenga la habilidad para hacer un ayate valora el saber de otra mujer (la madre), pero además asegura que la mujer al llegar al matrimonio será capaz de amortiguar los costos de la actividad agrícola a través del ahorro en la compra de implementos de trabajo (ayates, costales, morrales). El ayate tiene múltiples usos, cargar la cosecha, el zacate, la hierba, aplicar abono (químico y animal), leña y botes de agua. Tales actividades agrícolas no son exclusivas de los varones, sino que registran también una amplia participación de las mujeres, de modo que las otomíes no solo son responsables de la confección de esos instrumentos, sino también son usuarias de ellos.

Una otomí adulta tiende su telar en el patio o el solar y teje requiriendo a menudo de las ayudas para acercarse los instrumentos del telar.

Mi abuelita era muy buena para tejer, todos los días llegaba de cuidar sus borregas y se sentaba con su telar, y casi siempre nos llamaba para hacerle algún mandado, me ordenaba ba ehe gi guändi ma bät’i- ¡ven a mover mi telar!, o -ba tu ma jäxi- ¡tráeme mi ixtle! Ya cuando fui más grande, un día, bien enojada me dijo, ¡ayi muchacha, tu 
n’omás el juego, iya piensa en aprender cómo vas a hacer un ayate! Cuando te cases, ¿qué le vas a dar a tu esposo cuando te pida pa’ trabajar? Cuando me casé, mi mamá me regaló un ayate, un morral y unas bolas de ixtle, y me acuerdo que dijo, llévate esto pa' que le des a tu señor cuando se va a la milpa, ya cuando tú tengas tu ixtle, le haces uno de tu cuenta. Cuando aprendí yo a tejer le hice uno a mi esposo, me hice uno pa’ mí y así le fui tejiendo pa’ mis hijos, se acaba uno y ya está l’otro (Josefa, 47 años).

No siempre se aprende por libre vocación o por voluntad desprendida de interés, sino para un mejor desempeño de los roles de la mujer en el hogar. El saber se extiende como la extensión de un rol femenino, y a través de este se da la contribución de las mujeres en la esfera productiva, en la producción del alimento de la familia.

\section{BORDAR EL SABER Y EL SABER BORDAR}

El tejido del vestuario típico de la sociedad femenina otomí de Pueblo Nuevo encierra otras categorías de conocimientos en los cuales la observación no es suficiente para su aprehensión. Se requiere de aptitudes y actitudes para poder reconocer su identidad de género y etnia, donde haya un valor por los ancestros y su historia. Estos tejidos y bordados tienen una simbología tramada que se divide en los siguientes tipos: a) fitolátrica (plantas); b) zoomorfa (animales); c) elementos cósmicos (Tierra, Luna), y d) antropomorfa (mujer y hombre) (Vázquez, 2000). La simbología tramada en las prendas de las mujeres otomíes manifiesta una forma de conocimiento y sabiduría femeninas, una forma de comunicación, que expresa la relación armónica de hombres y mujeres otomíes con la naturaleza, el cosmos y la tierra. El conocimiento de bordar y tejer sigue siendo considerado patrimonio de las mujeres otomíes; por tanto, es de su interés procurar la preservación de este patrimonio cultural y social.

Los saberes implícitos en esta simbología han sido de forma no escrita, como componente de la tradición oral. Las otomíes, cuando relatan su historia, cuentan las dificultades materiales que las han hecho vulnerables al hambre, la discriminación por su condición de indígenas, al tiempo que dejan ver cómo parte de su patrimonio intangible y su «saber 
hacer» les permiten recobrar su dignidad de personas. En hogares de extremas dificultades económicas, el saber tejer y bordar de las mujeres amortiguó gastos en sus familias. Hubo en la comunidad grades tejedoras y grandes bordadoras que tuvieron como único medio de trabajo su telar, la aguja y su experiencia. Muchas de ellas acabaron con una vista deteriorada por exponerse a trabajar en las noches iluminadas tan solo por la luz de las velas, la quema de rajas de ocote, la lámpara de petróleo o de alcohol.

Aunado a lo anterior, se encuentra el trabajo invertido en la obtención del hilo de lana para tejer y bordar las prendas (faja, quesquémetl). Esta labor consiste de trasquilar el borrego, lavado y secado, escarmenado, cardado de la lana. El conocimiento de las mujeres en estas fases les permite elaborar un hilo de calidad y, a su vez, una prenda de calidad. En su estado natural se obtiene hilo de color blanco y negro, aunque también se puede hacer el teñido de la lana con plantas locales o tintes sintéticos para obtener colores vivos. De este modo resultan más atractivas las combinaciones que se plasman para el tejido del quesquémetl, las fajas y para el tramado de la simbología en estas últimas.

El telar de cintura en las otomíes es un símbolo con el que se construye la identidad de género, simultáneamente con la identidad cultural del grupo otomí. Derivada exclusivamente del oficio de tejedoras, tal identidad aparece como otra vía bajo la cual se conciben como «mujer ideal». Es decir, el patrón ideal de la mujer otomí está en el ser excelente una tejedora que elabore bonitos quesquémetl, fajas, ayates, etc. Esta es una valoración proveniente de ambos géneros y convierte a este oficio (tejedora) en destino para toda otomí.

Yo aprendí de todo, ¿por qué no iba aprender?, si crecí y todas crecimos viendo lo que sabían hacer nuestras mamás. La que no sabía nada consiste en su mamá que no sabía nada. A mí mi mamá me decía: ¡hazle así hija!, pa’ que no vas a sufrir cuando tengas tus hijos, cuando tu esposo te pide algo pa’ que se cobije. Aquí todas saben tejer, ¿cómo no van a saber?, si aquí se nacieron, se crecieron. Están locas las que dicen «no sé nada»; 
nomás niegan pa' no trabajar. -Nugo di pe ra r’onjua, ra bäti, götho di padi-. Yo tejo ayates, fajas; todo sé tejer (Juana, 57 años).

Se afirma que las mujeres aprenden a tejer y bordar para dar respuesta a sus deberes de ser mujer; en el caso de no asumir este saber como norma, caen en los cuestionamientos, incluso genéricos, del no saber servir a los demás.

El dominio de la técnica, la acertada combinación de los colores acorde con la simbología, así como la concentración o habilidad para reflexionar sobre su hacer, eran garantía para ser una tejedora reconocida. Por su condición de género subordinado, las mujeres no asistieron a la escuela, pero aprendieron a contar, sumar y restar en su oficio de tejedoras, especialmente para tramar las combinaciones de elementos: pájaros, venados, conejos, estrella, hombre y mujer. La ayuda de las más experimentadas fue determinante.

A nuestro parecer, en la elaboración de la faja existe una mayor colectivización del trabajo y saber femeninos. Aparentemente, es un saber que se comparte entre mujeres y no hay lugar para el egoísmo; por el contrario, existe un gran interés de las otomíes por compartir su técnica para hacer una faja. Hay una actitud positiva para reproducir el conocimiento que ya no es individual, sino colectivo. Hacer una faja es un saber individual que proviene del colectivo; es decir, de cualquiera de las otras mujeres otomíes de la misma comunidad; pero ese saber, al ser transmitido a otra mujer, esta lo convierte en particular. El saber hacer fajas casi siempre pone a prueba las capacidades y habilidades de las otomíes.

...A mí se me hizo muy difícil, yo aprendí ya de grande, será por eso que sufrí mucho.... me enseñó una prima que era re-buena gente, me tenía mucha paciencia y nunca se enojaba. Dos semanas dure pegada al telar, todo el santo día ahí hasta que aprendí, y es que yo no sabía contar, mi prima tampoco, pero lo que ella hacía era igualar lo que tenía para muestra, la otra faja, o la sabana o el ayate. Entonces tendía los montoncitos de lana o ixtle separados, ella ya sabía cómo poner los pares, la trama y todo, me decía, fíjate bien porque si pones uno mal ya se echó a perder todo, y tienes que volver a empezar. Un día me desesperé y le dije a mi prima: ¡Ay, esto es muy 
difícil!...ya mejor me voy a mi casa. Me contestó ella en otomí, ¿Se te hace difícil verdad?; no te enojes, si vas a aprender, y cuando aprendas, iqué tantas cosas vas a tejer!. Yo sentía que mi prima pensaba de mí ¡ay, esta es bien burra! Ya me regresaba a la casa bien triste, ni hambre me daba. Mi mamá n’amás decía, Ya ga pengi t’uxu, ba ehe gi tsir hme ¿Ya regresaste hija?, ¡vente a comer una tortilla!; -Ingi ne me-no tengo hambre mamá, le contestaba yo. Ya tsir hme ingi bengu t’uxu- Ya come, no te apures hija, me decía mi mamá... Y así era todos los días, hasta que por fin un día ya pude tejer yo sola una cuarta; ¡uy! estábamos re contentas. Me dijo mi prima, ora sí, vete a tu casa, llévate tu telar. Y ya me vine re contenta con mi telar. Cuando llegué le enseñé a mi mamá, y le dije, ora si má', ¡qué me dura un telar! Tengu bät’i ingi pe, di pe gothör nde, nupya di pe, pe ya bi nzöbi, ya ingi nu xa zö - ¿cuántas fajas no tejí yo?, todas las tardes me sentaba a tejer, las que no sabían, querer que no, cualquiera me mandaba a tejer una faja; ora sigo tejiendo pero ya me canso mucho, ya no veo bien (María, 82 años).

Aprender a tejer las fajas, por ser objetos donde se traman figuras, es supremamente difícil, y ciertas veces se realiza a costa del sufrimiento femenino y el miedo a ser rechazadas por no cumplir con lo que de ella se espera. Ellas aprenden y enseñan con las limitaciones culturales y económicas de que son objeto. Muchas de estas mujeres solo hablaban el otomí y lo tuvieron como idioma de instrucción: contar y orientar el aprendizaje.

También se puede leer en el testimonio que los retos de aprender a tejer están dados por la demostración de sus capacidades y el gusto de portar algo tan íntimo, como es la faja, hecho con sus propias manos. Una faja es la compañera íntima de una mujer otomí, una prenda de uso personal que la acompaña durante toda la vida e incluso en la muerte ya que en ciertos casos, cuando las prendas no alcanzan a ser heredadas, se van con su dueña. Las mujeres son enterradas con las prendas que haya hecho con sus manos, esfuerzo físico y conocimiento (fajas, quesquémetl y sábana). Parecen parte de su propiedad y cada prenda tiene un contenido vivencial de la cotidianidad, un saber implícito que se lleva hasta la muerte. 
El habla otomí y los saberes van unidos en todo ese proceso. Ellas los han aprendido y conservado por medio de su uso cotidiano. Necesariamente, el idioma ha sido el único instrumento con el que se pueden interpretar los símbolos y las técnicas implicadas en las prendas de vestir. Ellas explican, además, la relación hombre y mujer otomí con el cosmostierra, como madre protectora y dadora de vida.

\section{CONCLUSIONES}

A juzgar por lo aquí descrito, las mujeres otomíes poseen conocimientos y saberes contenidos en sus prácticas económicas, sociales y culturales. Como género femenino han establecido estrategias de enseñanza del idioma y de los saberes. La cercanía de las mujeres a un amplio campo de acción no las supone como únicas transmisoras del idioma, pero sí las más implicadas. La tarea de prolongar el idioma y el conjunto de saberes otomíes se ve fortalecida por otros elementos de contexto donde ocurren las interacciones cotidianas. Ello no impide acotar que la relación entre idioma y saberes está estructurada por factores de género y generación, relacionados con la producción y reproducción, donde las divisiones de trabajo que determinan la experiencia también determinan los saberes soportados en esa experiencia.

El idioma otomí ha sido el primer saber que facilita la aprensión de otros saberes otomíes. A través de este, hombres y mujeres pueden comprender y explicar el contenido y significado de los elementos de la naturaleza, el cosmos y la tierra, presentes en la vida de cada uno de los integrantes de la etnia otomí.

Finalmente, para explicar la permanencia o disminución del habla del idioma indígena, hay que ir más allá del análisis de los «papeles de las mujeres» y la división social del trabajo, hay que integrar al análisis otros elementos que den detalle sobre cómo se están conformando y hacia dónde van los intereses de los géneros y las generaciones para mantener o dejar de hablar otomí. 


\section{BIBLIOGRAFÍA}

Benvensite, Émile, 1999, Problemas de lingüística general, Siglo XXI, 20a. edición, México.

Berger, Peter y Thomas. Luckmann, 1979, La construcción social de la realidad, Amorrortu, Buenos Aires, Argentina.

Buxó Rey, María Jesús, 1988, Antropología de la mujer; cognición, lengua e ideología cultural, Arthropos, Madrid, España.

Castañeda, Salgado, Martha Patricia, 2006, «La antropología feminista hoy: algunos énfasis claves», en Revista Mexicana de Ciencias Políticas y Sociales, mayo-agosto, año/vol. XLIII, número 197, Universidad Nacional Autónoma de México, pp. 35-47.

Gregorio Gil, Carmen, 2006, «Contribuciones feministas a problemas epistemológicos de la disciplina antropológica: Representación y relaciones de poder», en AIBR, Revista de antropología Iberoamericana, Ed. electrónica, vol. 1 enero-febrero, pp. 22-39.

Harding, Sandra, 1987, «Introduction: ¿'Is there a feminist method?», en Feminism and Methodology, compilado por Sandra Harding, Indiana University Press, Blooington, Estados Unidos, pp. 1-4.

Heller, Agnes, 1991, Sociología de la vida cotidiana, Península, Barcelona, España.

Hernández, Castillo, R. Aída, 2003, «Re-pensar el multiculturalismo desde el género. Las luchas por el reconocimiento cultural y los feminismos de la diversidad», en Revista de estudios de género La ventana, diciembre, número 018, Universidad Guadalajara, Guadalajara, México, pp. 9-39. 
Irigaray Luce, 2002, La question de l'autre. Labrys: études feministes, numéro 1-2, juilletDécembre, Paris, France.

Instituto Nacional de Geografía, Estadística e Informática, Principales resultados del Censo de Población y Vivienda, 2010, México.

Lagarde, Marcela, 1990, Los cautiverios de las mujeres: madresposas. Monjas y putas, presas y locas, Facultad de Filosofía y Letras, Universidad Nacional Autónoma de México, México.

Maier, Elizabeth, 1998, «Aplicaciones y limitaciones de la categoría de género», en Revista Frontera Norte, vol.10, núm.20, julio-diciembre, Tijuana, México.

Toledo, Víctor M, y Narciso Barrera-Bassols, 2008, La memoria biocultural. La importancia ecológica de las sabidurías tradicionales. Perspectivas Agroecológicas, Editorial Icaria, Barcelona, España.

Vázquez, Ignacio, 2000, «Cuerpo y Textil Mazahua», Tesis de maestría, Facultad de Antropología, Universidad Autónoma del Estado de México, Toluca, México.

Fecha de recepción: 11 de enero de 2011.

Fecha de aceptación: 6 de enero de 2012. 